División de Pediatría.

${ }^{2}$ Departamento de

Hematología Oncología

Pontificia Universidad

Católica de Chile.

Servicio de Banco de

Sangre, Facultad de

Medicina Pontificia

Universidad Católica de

Chile.

${ }^{4}$ VidaCel.

${ }^{5}$ Servicio de Obstetricia y

Ginecología Clínica Santa María.

${ }^{6}$ División de Obstetricia y Ginecología Facultad de Medicina Pontificia Universidad Católica de Chile. aTM.

bLicenciado en Ciencias Biológicas.

Este trabajo ha sido

financiado parcialmente por Innova Chile, VidaCel y

Fundación Genómika.

Este trabajo recibió financiamiento de Innova

Chile y VidaCel. Las maternidades involucradas participaron de forma voluntaria.

Recibido el 16 de noviembre de 2012, aceptado el 24 de mayo de 2013

Correspondencia a: Francisco Barriga

División de Pediatría PUC, Departamento de Hematología Oncología

Facultad de Medicina Pontificia Universidad Católica de Chile.

E-mail: fbarriga@med. puc.cl.

\section{Trasplante alogénico de precursores hematopoyéticos de sangre de cordón umbilical de donante no emparentado: primera experiencia, en tres casos, con donantes del banco público chileno de células de cordón}

\author{
FRANCISCO BARRIGA ${ }^{1}$, ANGÉLICA WIETSTRUCK ${ }^{1}$, NICOLÁS ROJAS ${ }^{1}$, \\ PABLO BERTIN ${ }^{2}$, ISABEL PIZARRO ${ }^{3, a}$, AMANDA CARMONA $^{4, b}$, \\ ALEJANDRO GUILOF ${ }^{4}$, IVÁN ROJAS ${ }^{5}$, ENRIQUE OYARZÚN ${ }^{6}$
}

\section{Allogenic hematopoietic stem cell transplantation with unrelated cord blood. Report of three cases from the Chilean cord blood bank}

\begin{abstract}
Public cord blood banks are a source of hematopoietic stem cells for patients with hematological diseases who lack a family donor and need allogeneic transplantation. In June 2007 we started a cord blood bank with units donated in three maternity wards in Santiago, Chile. We report the first three transplants done with cord blood units form this bank. Cord blood units were obtained by intrauterine collection at delivery. They were depleted of plasma and red cells and frozen in liquid nitrogen. Tests for total nucleated cells, CD34 cell content, viral serology, bacterial cultures and HLA A, B and DRB1 were done. Six hundred cord blood units were stored by March 2012. Three patients received allogeneic transplant with cord blood from our bank, two with high risk lymphoblastic leukemia and one with severe congenital anemia. They received conditioning regimens according to their disease and usual supportive care for unrelated donor transplantation until full hematopoietic and immune reconstitution was achieved. The three patients had early engraftment of neutrophils and platelets. The child corrected his anemia and the leukemia patients remain in complete remission. The post-transplant course was complicated with Epstein Barr virus, cytomegalovirus and BK virus infection. Two patients are fully functional 24 and 33 months after transplant, the third is still receiving immunosuppression.
\end{abstract}

(Rev Med Chile 2013; 141: 1064-1067).

Key words: Anemia, Diamond-Blackfan; Blood banks; Cord blood stem cell transplantation; Leukemia; Unrelated donors.
E 1 empleo de sangre de cordón umbilical (SCU) de donante no relacionado es una alternativa para pacientes que necesitan trasplante de células progenitoras hematopoyéticas y no tienen donante familiar, especialmente en el grupo pediátrico $^{1-5}$. La habilitación de numerosos bancos que almacenan este producto ha permitido su uso cada vez más frecuente, estimándose que en la actualidad se han realizado más de 6.000 trasplantes con las más de 500.000 unidades guardadas mundialmente en bancos de SCU en el mundo. La mayoría de los pacientes beneficiados 
son portadores de neoplasias y otras patologías hematológicas ${ }^{6-9}$. El uso de SCU ofrece varias ventajas, dentro de las cuales destacan un menor requerimiento de compatibilidad, ausencia de riesgo para el donante, disponibilidad inmediata de la unidad una vez identificada y menor incidencia de enfermedad de injerto contra huésped ${ }^{10}$.

En 2007 implementamos un banco de SCU de acceso público en Chile con sangre donada en tres maternidades de Santiago, con el objetivo de mejorar las oportunidades de contar con este recurso para cualquier paciente que lo necesitara. El presente trabajo pretende dar cuenta de los resultados de los primeros tres trasplantes usando sangre proveniente de este banco.

\section{Métodos}

\section{Implementación del banco de cordón}

Las unidades de sangre de cordón fueron donadas por pacientes atendidas en las maternidades del Hospital Clínico y la Clínica San Carlos de la Pontificia Universidad Católica de Chile desde 2007 y en Clínica Santa María desde 2009. Las pacientes completaron una encuesta de donación y firmaron una autorización para el procedimiento. La sangre fue recolectada del cordón umbilical durante el alumbramiento en una bolsa con anticoagulante. Las unidades se depletaron de plasma y eritrocitos, fueron suspendidas en dextran y dimetilsulfoxido y congeladas en nitrógeno líquido ${ }^{11,12}$. Se realizó serología habitual para donantes de sangre en muestras maternas (virus de hepatitis B y C, HIV, HTLV-I, Chagas, VDRL). Se hicieron recuentos celulares de precursores hematopoyéticos (CD34+), viabilidad, grupo y $\mathrm{Rh}$, hemocultivo corriente y análisis de HLA A y B en baja resolución y DRB1 en alta resolución.

\section{Búsqueda de unidades compatibles}

Las búsquedas se hicieron comparando antígenos de histocompatibilidad (HLA) entre paciente y unidad de SCU, seleccionando aquellas que fueran idénticas en 5 ó 6 de los antígenos analizados. En las unidades compatibles se buscó una dosis celular mínima de $3 \times 10^{7}$ células nucleadas totales por kilo del paciente receptor, alcanzada mediante una o dos unidades de SCU, compatibles entre $\mathrm{s}^{13}$.

\section{Trasplante de sangre de cordón umbilical}

Las unidades se descongelaron y reconstituyeron en albúmina y dextran, se eliminó el excedente de dimetilsulfóxido y se infundieron rápidamente por una vía venosa central. Los pacientes recibieron cuidado de soporte habitual para trasplante de donante no emparentado. A los 30 días del trasplante se realizó estudio de ADN mediante técnica de short tandem repeats post trasplante por análisis de secuencias cortas repetidas (STR AmpF/STR Identifiler, Applied Biosystems) para definir quimerismo o cual proporción de células del paciente receptor son de origen del donante.

\section{Reporte de casos}

\section{Paciente 1}

Paciente de 43 años con diagnóstico de leucemia linfoblástica aguda portadora de cromosoma Filadelfia en primera remisión (Tabla 1). Se identificó un injerto de dosis adecuada con dos unidades compatibles, en el Banco de Sangre de St. Louis (USA) y Chile (Tabla 1). El paciente tuvo recuperación hematológica precoz y el estudio de quimerismo demostró que más de $95 \%$ de leucocitos provenían de precursores de la unidad chilena. Durante el período post trasplante presentó hematuria por virus $\mathrm{BK}$, reactivación asintomática de citomegalovirus, neumonía por Pneumocystis jirovecii y síndrome linfoproliferativo por Epstein Barr ${ }^{14}$, con respuesta a tratamiento específico en todos los casos. A cuatro años del trasplante el paciente realiza actividad laboral y familiar normal.

\section{Paciente 2}

Menor de 4 años con anemia Blackfan Diamond refractaria a corticoides recibiendo transfusiones mensuales de glóbulos rojos, en tratamiento quelante por ferritina sérica de hasta $1.589 \mathrm{ng} /$ ml. Recibió trasplante con una unidad (Tabla 1), obteniendo recuperación hematológica e inmunológica lentas con quimerismo completo a los 30 días. Su curso post trasplante fue complicado por un síndrome linfoproliferativo por Epstein Barr con compromiso de vía aérea superior que requirió traqueotomía, hematuria por virus BK y neumonía por coronavirus. A 26 meses de trasplantado hace vida escolar normal escolar sin tomar medicamentos y con traqueotomía cerrada. 
Tabla 1. Diagnóstico de los pacientes, características de los injertos de sangre de cordón y datos de recuperación post trasplante

\begin{tabular}{|c|c|c|c|}
\hline & Paciente 1 & Paciente 2 & Paciente 3 \\
\hline Edad & 49 & 4 & 5 \\
\hline Diagnóstico & $\begin{array}{l}\text { Leucemia linfoblástica aguda } \\
\text { cromosoma Filadelfia en } \\
\text { primera remisión }\end{array}$ & $\begin{array}{l}\text { Anemia Blackfan Diamond } \\
\text { refractaria a corticoides }\end{array}$ & $\begin{array}{l}\text { Leucemia linfoblástica aguda } \\
\text { en } 2^{a} \text { remisión con enferme- } \\
\text { dad residual positiva }\end{array}$ \\
\hline Condicionamiento & $\begin{array}{l}\text { Fludarabina, ciclofosfamida, } \\
\text { radioterapia corporal total }\end{array}$ & $\begin{array}{l}\text { Fludarabina, busulfan, ciclo- } \\
\text { fosfamida, timoglobulina }\end{array}$ & $\begin{array}{l}\text { Fludarabina, ciclofosfamida, } \\
\text { radioterapia corporal total }\end{array}$ \\
\hline Compatibilidad HLA & $\begin{array}{l}\text { Unidad 1: } 5 \text { de } 6 \\
\text { Unidad 2: } 5 \text { de } 6\end{array}$ & Unidad 1: 5 de 6 & Unidad 1: 5/6 \\
\hline $\begin{array}{l}\text { Células nucleadas } \\
\text { criopreservadas por kilo }\end{array}$ & $4,8 \times 10^{7}$ & $14 \times 10^{7}$ & $10 \times 10^{7}$ \\
\hline $\begin{array}{l}\text { Células CD34+ } \\
\text { criopreservadas por kilo }\end{array}$ & $2,5 \times 10^{5}$ & $12 \times 10^{5}$ & $16 \times 10^{5}$ \\
\hline Neutrófilos > 500/mm³ & Día + 15 & Día + 19 & Día + 12 \\
\hline Neutrófilos $>1.000 / \mathrm{mm}^{3}$ & Día + 17 & Día + 29 & Día + 14 \\
\hline Plaquetas > 20.000 & Día + 38 & Día + 65 & Día +28 \\
\hline Quimerismo día 30 & $>95 \%$ unidad 1 & $>95 \%$ & $>95 \%$ \\
\hline $\begin{array}{l}\text { Enfermedad de injerto } \\
\text { versus huésped }\end{array}$ & NO & NO & NO \\
\hline Linfocitos CD4 > 200 & +50 & Día + 365 & No alcanzado día + 85 \\
\hline
\end{tabular}

\section{Paciente 3}

Menor de 5 años con leucemia linfoblástica aguda portadora de cromosoma Filadelfia en tratamiento por recidiva en sistema nervioso central, con enfermedad residual en médula ósea. Recibió trasplante con una unidad de SCU (Tabla 1). Tuvo reconstitución hematológica rápida y quimerismo completo sin complicaciones durante la fase post trasplante. Permanece en control con tratamiento inmunosupresor a 10 meses de realizado el procedimiento.

\section{Discusión}

El presente trabajo constituye el reporte de los primeros trasplantes de precursores hematopoyéticos con SCU de donante no emparentado del banco público chileno. Los tres pacientes recibieron injertos de celularidad y compatibilidad adecuada. Las complicaciones posteriores al procedimiento en los tres pacientes fueron habituales para este tipo de trasplante. En los tres se demostró quimerismo completo a los 30 días de la infusión de sangre de cordón y ninguno presentó enfermedad de injerto versus huésped.

Esta experiencia inicial abre una nueva posibilidad para los pacientes con indicación de trasplante alogénico y viene a paliar una necesidad no satisfecha en nuestro medio y nuestro continente. El reporte anual de la World Marrow Donors Association (WMDA) ${ }^{15}$ de 2010 muestra que apenas $1,2 \%$ de las reservas de SCU para trasplante se encuentra en Sudamérica y sólo 0,4\% de los trasplantes con SCU en ese año fueron con unidades aportadas por bancos sudamericanos (Brasil y Argentina). Por otra parte, una encuesta realizada entre 2009 y 2011 de la actividad de trasplante alogénico de precursores hematopoyéticos en Chile ${ }^{16}$ mostró que en nuestro país se efectúan 4 trasplantes por millón de habitantes al año, que comparados con los 10 a 32 por millón de habitantes año en Europa y Estados Unidos de Nortemárica deja un amplio margen de mejoría.

Es de notar que este procedimiento se reserva para pacientes jóvenes con patologías letales para 
los cuales la mejor posibilidad de sobrevida es el trasplante. Por todo ello la implementación local de un banco de SCU de acceso universal tendrá un impacto decisivo en las oportunidades de sobrevida de estos pacientes y permitirá aportar unidades al inventario mundial de sangre de cordón.

Agradecimientos: Los autores agradecen la colaboración de los doctores Pablo Rubinstein (New York Blood Center, USA) y Joan García (Netcord) en la implementación del banco público de sangre de cordón en Chile.

\section{Referencias}

1. Broxmeyer HE, Douglas GW, Hangoc G, Cooper S, Bard J, English D, et al. Human umbilical cord blood as a potential source of transplantable hematopoietic stem/ progenitor cells. PNAS 1989; 86: 3828-32.

2. Kurtzberg J, Laughlin M, Graham ML, Smith C, Olson JF, Halperin EC, et al. Placental blood as a source of hematopoietic stem cells for transplantation into unrelated recipients. N Engl J Med 2009; 335: 157-66.

3. Rubinstein P, Carrier C, Scaradavou A, Kurtzberg J, Adamson J, Migliaccio AR, et al. Outcomes among 562 recipients of placental-blood transplants from unrelated donors. N Engl J Med 1998; 339: 1565-77.

4. Eapen M, Rubinstein P, Zhang MJ, Stevens C, Kurtzberg J, Scaradavou A, et al. Outcomes of transplantation of unrelated donor umbilical cord blood and bone marrow in children with acute leukaemia: a comparison study. Lancet 2007; 369: 1947-54.

5. Gluckman E, Rocha V, Boyer-Chammard A, Locatelli F, Arcese W, Pasquini R, et al. Outcome of cord-blood transplantation from related and unrelated donors. N Engl J Med 1997; 337: 373-81.
6. Navarrete C, Contreras M. Cord blood banking: a historical perspective. Br J Haematol 2009: 147; 236-45.

7. Querol S, Rubinstein P, Marsh SG, Goldman J, Madrigal JA. Cord blood banking: 'providing cord blood banking for a nation'. Br J Haematol 2009; 147 (2): 227-35.

8. Brunstein CG, Wagner JE. Umbilical cord blood transplantation and banking. Annu Rev Med 2006; 57: $403-$ 17.

9. Bone Marrow Donors Worldwide (www.bmdw.org).

10. Rocha V, Wagner JE, Sobocinski KA, Klein JP, Zhang MJ, Horowitz MM, et al. Graft-versus-host disease in children who have received a cord-blood or bone marrow transplant from an HLA-identical sibling. N Engl J Med 2000; 342: 1846-54.

11. Quillen K, Berkman EM. Methods of isolation and cryopreservation of stem cells from cord blood. J Hematother 1996; 5 (2): 153-5.

12. Donaldson C, Armitage WJ, Denning-Kendall PA, Nicol AJ, Bradley BA, Hows JM. Optimal cryopreservation of human umbilical cord blood. Bone Marrow Transplant 1996; 18: 725-31.

13. Barker JN, Weisdorf DJ, DeForT E, Blazer B, McGlave PB, Miller JS. Transplantation of second partially HLAmatched umbilical cord blood units to enhance engra$\mathrm{ftment}$ in adults with hematologic malignancy. Blood 2005; 105: 1343-7.

14. Delaney C, Gutman JA, Appelbaum FR. Cord blood transplantation for haematological malignancies: conditioning regimens, double cord transplant and infectious complications. Br J Haematol 2009; 147: 207-16.

15. World Marrow Donor Association 2010 annual report (www.worldmarrow.org).

16. Barriga F. Realidad global del trasplante de precursores hematopoyéticos. XVIII Congreso Chileno de Hematología, octubre de 2012. http://www.hematologia.org/ bases/arch924.pdf 